ARTICLE

DOI: $10.1038 / s 41467-018-06246-6$

\title{
Copper-catalyzed methylative difunctionalization of alkenes
}

Xu Bao ${ }^{1}$, Takayuki Yokoe ${ }^{1}$, Tu M. Ha ${ }^{1}$, Qian Wang ${ }^{1}$ \& Jieping Zhu (i) ${ }^{1}$

Trifluoromethylative difunctionalization and hydrofunctionalization of unactivated alkenes have been developed into powerful synthetic methodologies. On the other hand, methylative difunctionalization of olefins remains an unexplored research field. We report in this paper the $\mathrm{Cu}$-catalyzed alkoxy methylation, azido methylation of alkenes using dicumyl peroxide (DCP), and di-tert-butyl peroxide (DTBP) as methyl sources. Using functionalized alkenes bearing a tethered nucleophile (alcohol, carboxylic acid, and sulfonamide), methylative cycloetherification, lactonization, and cycloamination processes are subsequently developed for the construction of important heterocycles such as 2,2-disubstituted tetrahydrofurans, tetrahydropyrans, $\gamma$-lactones, and pyrrolidines with concurrent generation of a quaternary carbon center. The results of control experiments suggest that the 1,2-alkoxy methylation of alkenes goes through a radical-cation crossover mechanism, whereas the 1,2-azido methylation proceeds via a radical addition and $\mathrm{Cu}$-mediated azide transfer process.

\footnotetext{
${ }^{1}$ Laboratory of Synthesis and Natural Products, Institute of Chemical Sciences and Engineering, Ecole Polytechnique Fédérale de Lausanne, EPFL-SB-ISICLSPN, BCH5304, Lausanne CH-1015, Switzerland. Correspondence and requests for materials should be addressed to J.Z. (email: jieping.zhu@epfl.ch)
} 
T he so-called magic methyl effect has long been known in medicinal chemistry and has been frequently used to optimize the biological and pharmacological properties of a drug candidate ${ }^{1}$. In addition to traditional nucleophilic substitution reaction, transition metal-catalyzed cross-coupling reaction has recently been developed into a powerful tool for the methylation of (hetero)aromatics ${ }^{2,3}$. However, in comparison to the recent advances in the field of trifluoromethylation of organic compounds ${ }^{4,5}$, progress on the development of new methylation protocols has been much slower. While the importance of the $\mathrm{CF}_{3}$ group in pharmaceuticals and crop science is undeniable, the $\mathrm{CH}_{3}$ group deserved certainly equal attention. In fact, it was estimated that over $67 \%$ of 200 top-selling drugs bore at least one $\mathrm{CH}_{3}$ group, while $<5 \%$ of the small molecule drugs in the same list contained a $\mathrm{CF}_{3}$ group ${ }^{6}$.

Most of the trifluoromethylative difunctionalization of alkenes involved the generation of electrophilic $\mathrm{CF}_{3}$ radical from the hypervalent iodine reagents ${ }^{7}$ followed by its addition to the electron-rich alkenes (Fig. 1a) $)^{3}$. Similarly, metal-catalyzed hydrofunctionalization of alkenes, pioneered by Mukaiyama in $1980 \mathrm{~s}^{8}$, has been extensively investigated (Fig. 1b) ${ }^{9-16}$. By choosing an appropriate radical acceptor, Baran and co-workers developed a protocol for the hydromethylation of unactivated alkenes for the one-pot conversion of alkenes to alkanes (Fig. 1c) ${ }^{15}$. Interestingly, in spite of the known magic methyl effect in medicinal chemistry and its utility in natural product synthesis, the related methylative difunctionalization of unactivated olefins was, to the best of our knowledge, far less developed and a multistep sequence was generally needed to accomplish this endeavor. As illustrated in Fig. 1d, five steps were needed to convert alkene I to hydroxymethylated derivative II, an advanced intermediate on the way to vinigrol 17,18 .

Peroxides undergo homolytic cleavage of the $\mathrm{O}-\mathrm{O}$ bond to generate acyloxy or alkoxy radicals, which can act as oxidants and radical initiators. These oxygen-centered radicals can also undergo further fragmentation to produce the alkyl radicals ${ }^{19}$. The groups of Kawazoe ${ }^{20}$ and Wong ${ }^{21}$ demonstrated in 1970 s that the methyl radical generated from tert-butyl hydroperoxide and tert-butyl peracetate can methylate the protonated nucleobases via homolytic aromatic substitution (HAS) reaction. These pioneering studies, akin to Minisci reaction ${ }^{22}$, is in line with the

a

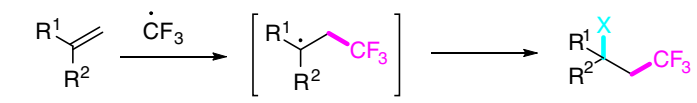

b
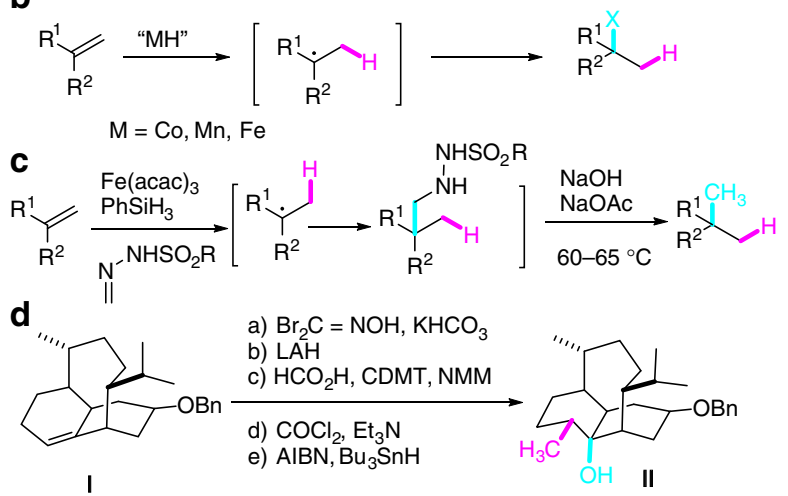

nucleophilic nature of the methyl radical. Since then, conditions allowing the methylation of (hetero)arenes ${ }^{23-26}$, amides/carboxylic acids ${ }^{27-30}$, and isocyanides ${ }^{31-34}$ have been exploited. In addition, methylation of electron-deficient olefins such as $\mathrm{N}$ arylacrylamides have also been developed ${ }^{35-38}$. In this latter case, the resulting electrophilic radical adduct underwent rapid intramolecular HAS with the tethered aromatic ring to afford 2,2disubstituted oxindoles. On the other hand, methylative difunctionalization of unactivated double bonds using peroxide as methyl source has, to the best of our knowledge, not been reported $^{39}$. This was probably due to the perception that methyl radical is nucleophilic, therefore, its addition to electron-rich alkenes would be polarity mismatched process ${ }^{40-43]}$. We report herein the realization of this endeavor by developing threecomponent 1,2-alkoxy methylation, 1,2-azido methylation, and methylative cycloetherification, lactonization, cycloamination of unactivated alkenes (Fig. 1e). The results of control experiments suggested that the 1,2-alkoxy methylation of alkenes went through a radical-cation crossover mechanism, whereas the azido methylation proceeded via a radical addition and $\mathrm{Cu}$-mediated redox azide transfer process.

\section{Results}

Three-component 1,2-alkoxy methylation of alkenes. Examples of alkoxy alkylation of unactivated alkenes are rare. Wang and coworkers reported a rhenium-catalyzed 1,2-acetoxy methylation of styrene derivatives using phenyliodine diacetate (PIDA) as both the methyl and the acetoxy sources ${ }^{44}$, while Glorius ${ }^{45}$ and $\mathrm{Bao}^{46,47}$ reported the alkoxy alkylation of alkenes via decarboxylative generation of alkyl radicals.

We began our studies by examining the 1,2-alkoxy methylation of a-methylstyrene (1a). After extensive survey of the reaction parameters varying the $\mathrm{Cu}$ sources, the ligands, the $\mathrm{Cu} /$ ligand ratio, the peroxides, the bases, the solvents, the concentration, and the reaction temperature, the optimum conditions found consisted of heating a $\mathrm{MeOH}$ solution of $\mathbf{1 a}(c 0.1 \mathrm{M})$ in a sealed tube in the presence of a catalytic amount of $\mathrm{Cu}\left(\mathrm{BF}_{4}\right)_{2} \cdot 6 \mathrm{H}_{2} \mathrm{O}(0.2$ equiv), 4,4-dimethoxy-2,2'-bipyridine (L1, 0.3 equiv) and $\mathrm{Na}_{2} \mathrm{HPO}_{4}\left(0.2\right.$ equiv) at $120^{\circ} \mathrm{C}$ for $4 \mathrm{~h}$. Under these conditions, 2a was isolated in $96 \%$ yield. We note that reaction using

e

Fig. 1 Functionalization of unactivated alkenes. a Trifluoromethylative difunctionalization of alkenes; b hydrofunctionalization of alkenes.

c hydromethylation of alkenes; d Example of 1,2-hydroxy methylation of alkene in natural product synthesis. Five steps were required to accomplish this transformation; e methylative difunctionalization of electron-rich alkenes: radical-metal mediated ligand transfer and radical-cation crossover processes. Abbreviations: $\mathrm{Fe}(\mathrm{acac})_{3}$ iron (III) acetylacetonate; LAH lithium aluminum hydride; CDMT 2-chloro-4,6-dimethoxy-1,3,5-triazine; NMM N-methyl morpholine; AIBN azobisisobutyronitrile 


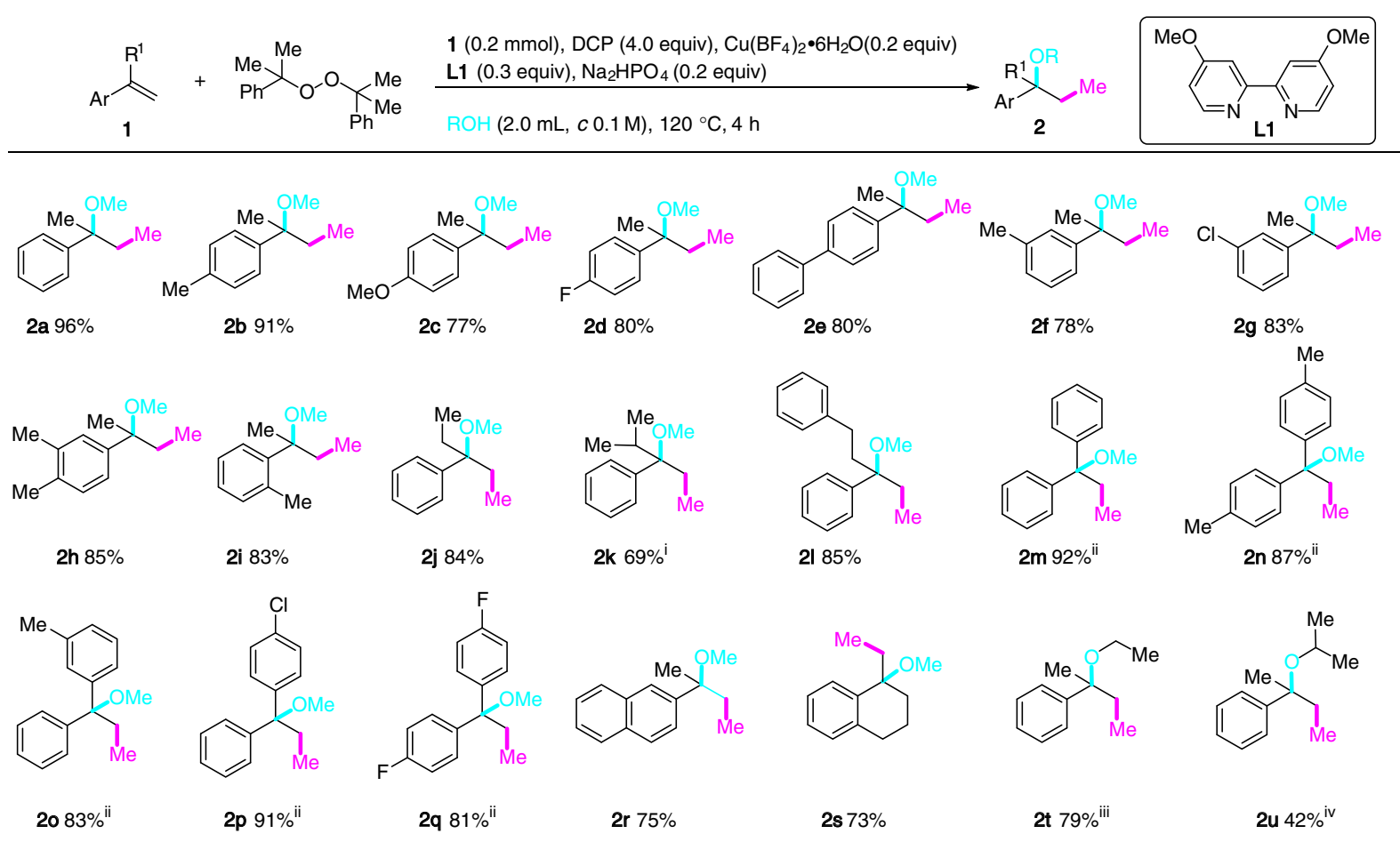

Fig. 2 1,2-Alkoxy methylation of unactivated alkenes. Unless specified, $\mathrm{MeOH}$ was used as solvent. (i) $140{ }^{\circ} \mathrm{C}$; (ii) DTBP (4.0 equiv) was used instead of DCP; (iii) EtOH (2.0 mL, c $0.1 \mathrm{M}$ ); (iv) $\operatorname{iPrOH}(2.0 \mathrm{~mL}$, c $0.1 \mathrm{M}$ ). Abbreviations: DTBP di-tert-butyl peroxide; DCP dicumyl peroxide

2-hydroperoxy-2-methylbutane as ethyl donor under otherwise standard conditions provided a complex reaction mixture.

The scope of this 1,2-alkoxy methylation of alkenes is shown in Fig. 2. Electron-donating ( $\mathrm{Me}$ and $\mathrm{OMe}$ ) and electronwithdrawing ( $\mathrm{F}$ and $\mathrm{Cl}$ ) substituents at different positions of the phenyl ring of the a-methylstyrene derivatives were transformed into the corresponding methylated ethers $(\mathbf{2} \mathbf{b}-\mathbf{2} \mathbf{i})$ in excellent yields. Different alkyl groups (Et, $i \mathrm{Pr}$, and $\mathrm{CH}_{2} \mathrm{CH}_{2} \mathrm{Ph}$ ) at the $\alpha-$ position of styrene were compatible $(\mathbf{2} \mathbf{j}-\mathbf{2 l})$ and the 1,1diarylethylenes were similarly difunctionalized to afford the desired products $(\mathbf{2} \mathbf{m}-\mathbf{2 q})$ regardless of the electronic nature of the substituents on the aromatic ring. 2-Vinylnaphthalene and 1methylene-1,2,3,4-tetrahydronaphthalene took part in the reaction to afford the three-component adducts without event (2r, 2s). However, styrene failed to give the desired 1,2-methoxy methylation product under standard conditions. Performing the reaction of $\mathbf{1 a}$ in ethanol and isopropanol under otherwise standard conditions afforded the ethyl ether (2t) and the isopropyl ether $(\mathbf{2 u})$, respectively. A gram scale experiment converted $\mathbf{1 a}$ to the three-component adduct $\mathbf{2 a}$ in $93 \%$ isolated yield.

Three-component 1,2-azido methylation of alkenes. There were only few examples on the three-component carboazidation of alkenes with the concurrent formation of a $\mathrm{C}\left(\mathrm{sp}^{3}\right)-\mathrm{C}\left(\mathrm{sp}^{3}\right)$ and a $\mathrm{C}$ $\left(\mathrm{sp}^{3}\right)-\mathrm{N}$ bond ${ }^{48}$. Renaud and co-workers developed a carboazidation of alkenes 1 employing electrophilic alkyl radicals generated from ethyl $\alpha$-iodoacetate and phenylsulfonyl azide as the azide sources ${ }^{49,50}$. Three-component 1,2-azido alkylation of alkenes with nucleophilic alkyl radical is to the best of our knowledge unknown ${ }^{51-53}$. The a-methylstyrene (1a) was chosen as a test substrate for the optimization of the 1,2-azido methylation process. Using $\mathrm{Cu}\left(\mathrm{BF}_{4}\right)_{2} \cdot 6 \mathrm{H}_{2} \mathrm{O}$ as catalyst (0.2 equiv), initial survey of the reaction conditions varying the methyl sources (DCP, DTBP, and tert-butyl peroxybenzoate), the azide sources $\left(\mathrm{TMSN}_{3}, \mathrm{NaN}_{3}, \mathrm{KN}_{3}\right.$, and $\mathrm{LiN}_{3}$ ) and solvents $(\mathrm{MeCN}$, $t \mathrm{BuCN}, \mathrm{DMF}, \mathrm{DMSO}, 1,4$-dioxane, and $t \mathrm{BuOH})$ prompted us to fix the following key parameters $\left[\mathrm{LiN}_{3}, \mathrm{DTBP}, t \mathrm{BuOH}(c 0.1 \mathrm{M})\right]$ for further optimization. The 1,10-phenanthroline L2 turned out to be a superior ligand than $\mathbf{L 1}$ and $\mathrm{CuSO}_{4}$ stood out as the catalyst of choice among those copper salts screened $\left[\mathrm{Cu}(\mathrm{OAc})_{2}\right.$, $\mathrm{Cu}(\mathrm{OTf})_{2}, \mathrm{CuF}_{2}$, and $\mathrm{CuSO}_{4}$ ]. Interestingly, reducing the loading of $\mathrm{CuSO}_{4}$ (0.01 equiv) gave a cleaner reaction mixture. Overall, under optimized conditions $\left[\mathrm{CuSO}_{4}\right.$ ( 0.01 equiv), $\mathbf{L 2}$ (0.03 equiv),

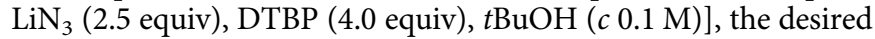
compound 3a was isolated in $81 \%$ yield (Fig. 3 ). A similar yield of 3a $(79 \%)$ was obtained when the 1,2 -azido methylation of 1 a was performed at $2.0 \mathrm{mmol}$ scale. Once again, using 2-hydroperoxy-2methylbutane as ethyl donor under otherwise standard conditions provided a complex reaction mixture.

The reaction was applicable to a variety of $\alpha$-methylstyrene derivatives bearing electron-donating ( $\mathrm{Me}$ and $\mathrm{OMe})$ and -withdrawing groups (4-Cl, 4- Br, 4-F, 4-OCF $3,4-\mathrm{CN}$, and $4-\mathrm{NO}_{2}$ ) on the phenyl ring. The presence of an o-methyl substituent in the substrate was also tolerated to afford 3k. $\mathbf{\alpha}$-Ethyl, $\alpha$-isopropyl and a-phenethyl styrenes participated in the reaction without event (3m-3o). The 1,1-diarylethylenes bearing substituents with different electronic properties were similarly converted to the three-component adducts $(\mathbf{3 p}-\mathbf{3 u})$.

Methylative cycloetherification. Metal-catalyzed arylative cycloetherification and cycloamination has been well developed for the synthesis of functionalized oxa- and aza-heterocycles ${ }^{54,55}$. The alkylation-induced heterocyclization is, on the other hand, poorly documented. For instance, only few examples of alkylative cycloetherification have been reported in the literature 56 .

We investigated the methylative cycloetherification of alkenes using 4-phenylpent-4-en-1-ol (4a, $\mathrm{R}=\mathrm{H}, n=1$, Fig. 4a) as a test substrate. Gratefully, treatment of a $t \mathrm{BuOH}$ solution of $4 \mathrm{a}$ under conditions established for the 1,2-alkoxy methylation of alkenes afforded the tetrahydrofuran $\mathbf{5 a}$ in $58 \%$ yield. Replacing DCP with DTBP gave a similar yield of 5a (57\%). Therefore, DTBP was used as a methyl source for further condition optimization as it provided a cleaner reaction mixture. Performing the reaction in 

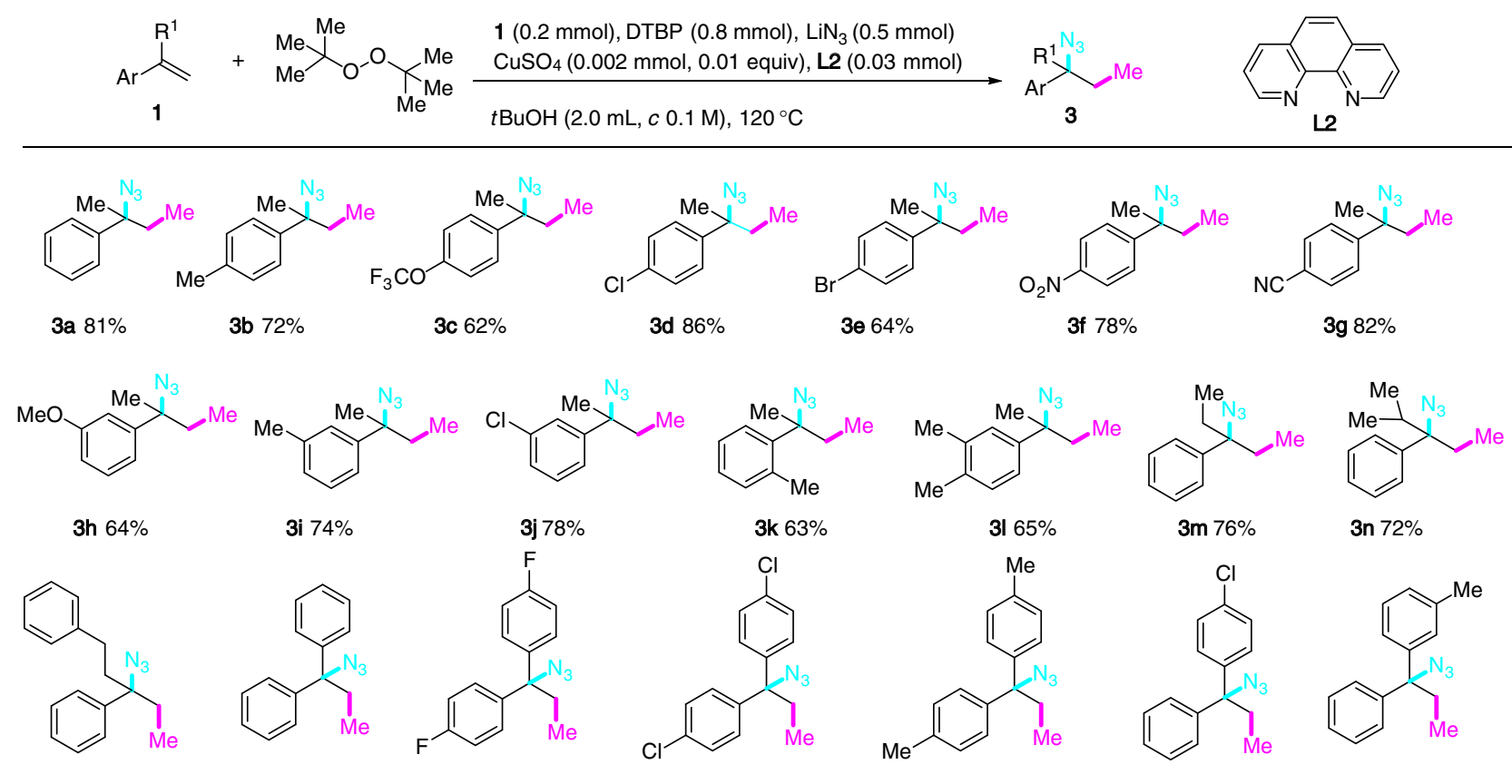

3o $\mathrm{Ph}, 63 \%$

$3 p 78 \%$

$3 q 54 \%$

3 r $85 \%$
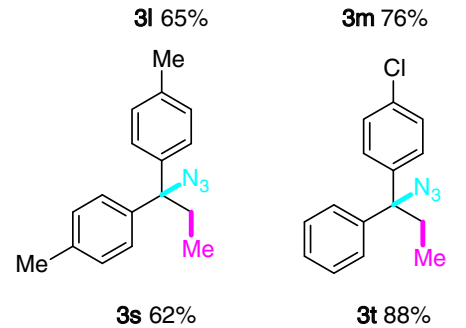

3n $72 \%$

Fig. 3 1,2-Azido methylation of unactivated alkenes. The reaction scheme is shown above the table

$t \mathrm{BuCN}$ furnished $\mathbf{5 a}$ in only $30 \%$ yield. Other solvents such as tetrahydrofuran (THF), dimethoxyethane (DME) and N,Ndimethylformamide (DMF) led to the decomposition or polymerization of 4a. Finally, trifluoroethanol (TFE) turned out to be an optimum solvent and $\mathrm{Cu}(\mathrm{OTf})_{2}$ a slightly better catalyst than $\mathrm{Cu}\left(\mathrm{BF}_{4}\right)_{2} \bullet 6 \mathrm{H}_{2} \mathrm{O}$ for this reaction. Overall, the reaction of $\mathbf{4 a}$ with DTBP in trifluoroethanol $(c 0.1 \mathrm{M})$ in the presence of $\mathrm{Cu}(\mathrm{OTf})_{2}$ (0.2 equiv), 4,4'-dimethoxy-2,2'-dipyridine (L1, 0.3 equiv), $\mathrm{Na}_{3} \mathrm{PO}_{4} \quad\left(0.2\right.$ equiv) at $120^{\circ} \mathrm{C}$ afforded 2-ethyl-2phenyltetrahydrofuran (5a) in $82 \%$ yield.

Under the above-optimized conditions, a diverse set of 4-aryl substituted pent-4-en-1-ols 4 underwent methylative cycloetherification to afford the 2,2-disubstituted tetrahydrofurans $(\mathbf{5 b}-\mathbf{5 m})$ in good yields (Fig. 4a). The reaction tolerated the presence of both electron-donating ( $\mathrm{Me}, \mathrm{OMe}, \mathrm{Ph}$, and $i \mathrm{Pr}$ ) and electronwithdrawing groups $(\mathrm{F}, \mathrm{Cl}, \mathrm{Br}$, and $\mathrm{CN})$ at different positions of the aryl ring. The 5-phenylhex-5-en-ol underwent the similar methylative cycloetherification to afford 2-ethyl-2-phenyltetrahydro- $2 \mathrm{H}$-pyran (5n) in $76 \%$ yield.

Methylative lactonization. $\gamma$-Butyrolactones are found in many bioactive compounds ${ }^{57}$ and are also useful building blocks in organic synthesis ${ }^{58}$. Consequently, many different synthetic routes have been developed for the synthesis of this important heterocycle ${ }^{59-64}$. Encouraged by the aforementioned results, the methylative lactonization of alkenes was next investigated. The optimum reaction conditions we found consisted of heating a solution of 6 in $t \mathrm{BuOH}(c 0.1 \mathrm{M})$ in the presence of $\mathrm{CuSO}_{4}(0.2$ equiv), 1,10-Phen (L2, 0.3 equiv), DTBP (4.0 equiv) and $\mathrm{Na}_{3} \mathrm{PO}_{4}$ ( 0.2 equiv) at $120^{\circ} \mathrm{C}$. As it is shown in Fig. $4 \mathrm{~b}$, electron-donating $(\mathrm{Me}, \mathrm{OMe}, \mathrm{Ph}$, and $i \mathrm{Pr}$ ) and electron-withdrawing groups $(\mathrm{F}, \mathrm{Br}$, $\mathrm{Cl}$, and $\mathrm{CN}$ ) on the phenyl ring of the a-methyl styrene derivatives were well tolerated leading to $\gamma$-lactones $(7 \mathbf{a}-7 \mathbf{i})$ in good yields. The (E)-4-phenylbut-3-enoic acid (6j), a 1,2-disubstituted alkene, underwent regioselective methylative lactonization to afford the 4,5-trans-disubstituted $\gamma$-lactone $7 \mathbf{j}$ as a single isolable diastereomer in $41 \%$ yield together with the methyl ester of $\mathbf{6 j}$ (24\%).
Methylative cycloamination. While trifluoromethylative cycloamination of alkenes have been reported recently ${ }^{65,66}$, the methylative counterpart is to the best of our knowledge unknown. We therefore set out to examine this reaction using sulfonamide as internal nucleophile. Optimum conditions found for the methylative cycloamination of 8a with DTBP (4.0 equiv) consisted of heating a solution of $\mathbf{8 a}$ in $t \mathrm{BuOH}(c 0.1 \mathrm{M})$ in the presence of $\mathrm{Cu}(\mathrm{OAc})_{2}$ (0.2 equiv), 1,10-Phen (L2) and $\mathrm{Na}_{3} \mathrm{PO}_{4}$ (0.2 equiv) at $120^{\circ} \mathrm{C}$. Under these conditions, the pyrrolidine 9a was isolated in $71 \%$ yield. As it is shown in Fig. 4c, electrondonating $(\mathrm{Me}, \mathrm{OMe}, \mathrm{Ph}$, and $i \mathrm{Pr}$ ) and electron-withdrawing groups $(\mathrm{F}, \mathrm{Br}, \mathrm{Cl}$, and $\mathrm{CN})$ on the phenyl ring of the a-methyl styrene derivatives were well tolerated leading to 2,2-disubstituted pyrrolidines (9a-9k) in good yields.

Mechanistic studies. Possible reaction pathways for the 1,2alkoxy methylation and 1,2-azido methylation of alkenes are depicted in Fig. 5a. Reduction of peroxide (DCP or DTBP) by the in situ generated $\mathrm{Cu}(\mathrm{I}) \mathrm{X}$ salt $\mathbf{A}$ would produce the tert-alkoxy radical $\mathbf{B}$ and $\mathbf{C u}(\mathrm{II})$ salt $\mathbf{C}$. Alternatively, thermal decomposition of peroxide would generate two molecules of alkoxy radical B. $\beta$ Scission of $\mathbf{B}$ would generate ketone $\mathbf{D}$ and methyl radical $\mathbf{E}$. Addition of $\mathbf{E}$ to the alkene would produce the benzyl radical $\mathbf{F}$ which would be oxidized by $\mathrm{Cu}(\mathrm{II})$ salt $\mathbf{C}$ to the carbenium $\mathbf{G}$ with the concurrent regeneration of the $\mathrm{Cu}(\mathrm{I}) \mathrm{X}$ salt. Trapping of the carbenium $\mathbf{G}$ by nucleophile would then afford the observed products (route a). Alternatively, radical $\mathbf{F}$ could be directly converted to the adduct via a $\mathrm{Cu}$-centered redox transfer process (route $\mathbf{b}$ ) or via radical rebound of $\mathbf{F}$ with $\mathbf{C}$ followed by reductive elimination of the resulting $\mathrm{Cu}(\mathrm{III})$ species $\mathbf{H}$ (route c) ${ }^{64}$.

Several experimental observations and the results of control experiments were in line with the proposed reaction pathway. First, 1,2-methoxy methylation of 1a was completely inhibited in the presence of 2,2,6,6-tetramethyl-1-piperidinyloxy (TEMPO, 10). 1-(Methoxy)-2,2,6,6-tetramethylpiperidine (11) was instead isolated in $29 \%$ yield (Fig. 5b). Second, submitting (1-cyclopropylvinyl)benzene (12) to the standard 1,2-methoxy methylation conditions afforded dihydronaphthalene $\mathbf{1 3}$ in $43 \%$ yield (Fig. 5c). These two experiments clearly indicated the existence of both the 

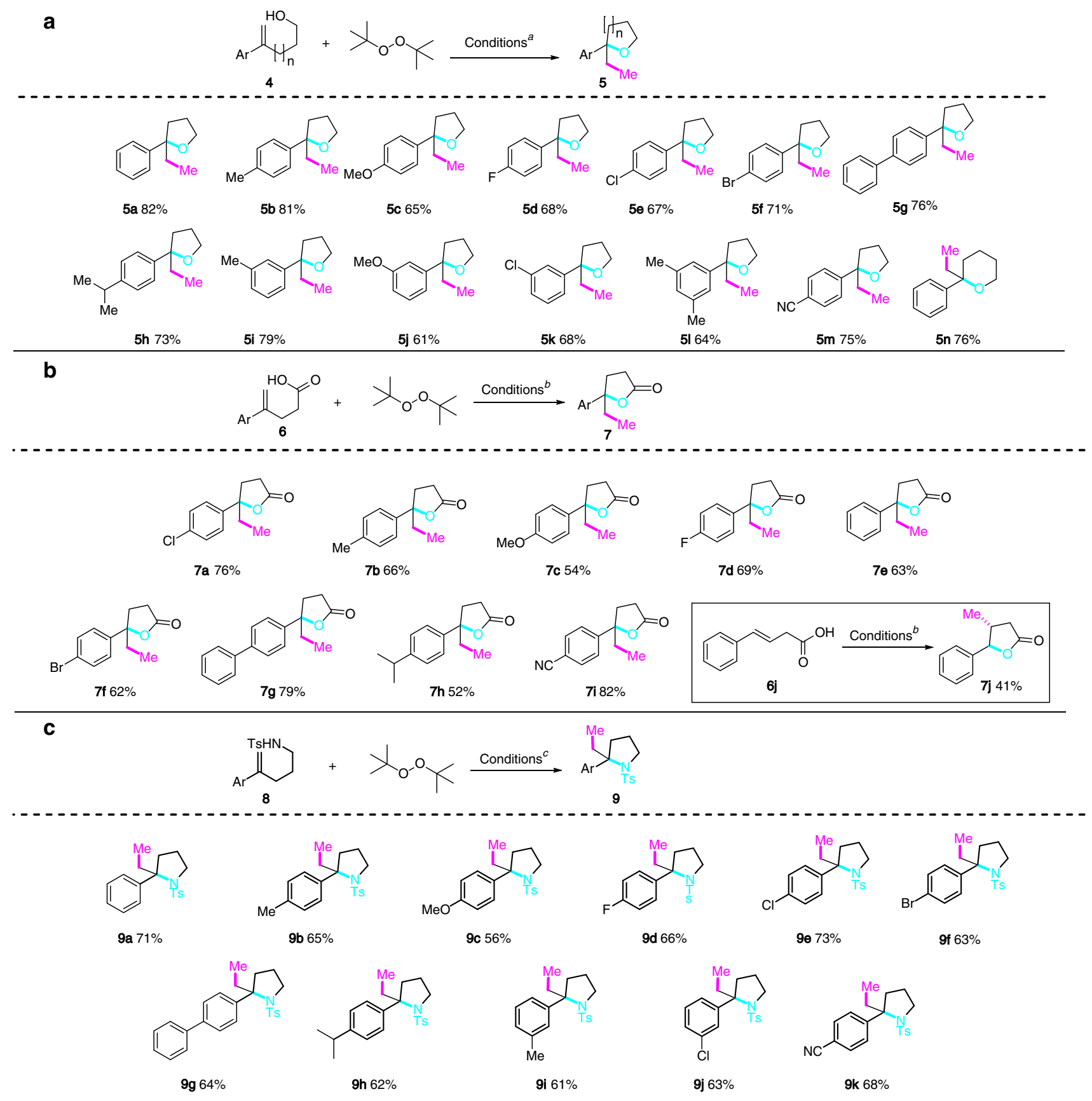

Fig. 4 Methylative heterocyclization of alkenes. a Methylative cycloetherification: $\mathbf{4}(0.2 \mathrm{mmol}), \mathrm{Cu}(\mathrm{OTf})_{2}\left(0.2\right.$ equiv), $\mathbf{L 1}(0.3 \mathrm{equiv}), \mathrm{Na}_{3} \mathrm{PO}_{4}(0.2 \mathrm{equiv})$, DTBP (4.0 equiv), $\mathrm{CF}_{3} \mathrm{CH}_{2} \mathrm{OH}$ (c $\left.0.1 \mathrm{M}\right), 120^{\circ} \mathrm{C}$. Yields refer to isolated products. b Methylative lactonization: 6 (0.2 mmol), CuSO $(0.2$ equiv), $\mathbf{L 2}$ (0.3 equiv), $\mathrm{Na}_{3} \mathrm{PO}_{4}$ ( 0.3 equiv), $\mathrm{DTBP}\left(4.0\right.$ equiv), $\mathrm{tBuOH}(\mathrm{c} 0.1 \mathrm{M}), 120^{\circ} \mathrm{C}$. c Methylative cycloamination: 8, Cu(OAc) $\left(0.2\right.$ equiv), $\mathbf{L 2}\left(0.3\right.$ equiv), $\mathrm{Na}{ }_{3} \mathrm{PO}{ }_{4}$ (0.2 equiv), DTBP (4.0 equiv), $\mathrm{tBuOH}(c 0.1 \mathrm{M}), 120^{\circ} \mathrm{C}$

methyl radical (Me•) and the adduct radical 14 in this threecomponent process. To gain further insight on the reaction mechanism, the 2-tert-butoxy-3-(1-phenylvinyl)cyclopropyl)benzene (15), developed by Newcomb as a supersensitive radical probe, was synthesized ${ }^{67,68}$. It has been demonstrated that the cyclopropane will be opened at the phenyl-bearing carbon in a radical mechanism and at the oxygen-bearing carbon in a cationic mechanism. Eventually, treatment of $\mathbf{1 5}$ under our methoxy methylation conditions afforded a quite complex reaction mixture from which 1,4-disubstituted naphthalene $\mathbf{1 6}$ was isolated in $17 \%$ yield. On the other hand, compound 15 was converted, under 1,2azido methylation conditions, cleanly to 16 in 56\% yield (Fig. 5d).
Formation of benzyl radical $\mathbf{1 7}$ followed by regioselective ring opening to 18 and intramolecular HAS reaction would provide dihydronaphthalene 20 which, upon elimination of $t \mathrm{BuOH}$, would afford naphthalene 16. The observed regioselective ring opening of cyclopropane supported the involvement of the benzylic radical 17 as a possible reactive intermediate.

The significant difference in the yield of $\mathbf{1 6}$ from radical clock probe $\mathbf{1 5}$ under the methoxy methylation and azido methylation conditions was intriguing. We tentatively attributed to the different oxidation power of the copper salts. $\mathrm{CuSO}_{4}$ is known to be a weaker oxidant than $\mathrm{Cu}\left(\mathrm{BF}_{4}\right)_{2} \bullet 6 \mathrm{H}_{2} \mathrm{O}$, the benzylic radical generated under the azido methylation conditions $\left(\mathrm{CuSO}_{4^{-}}\right.$ 

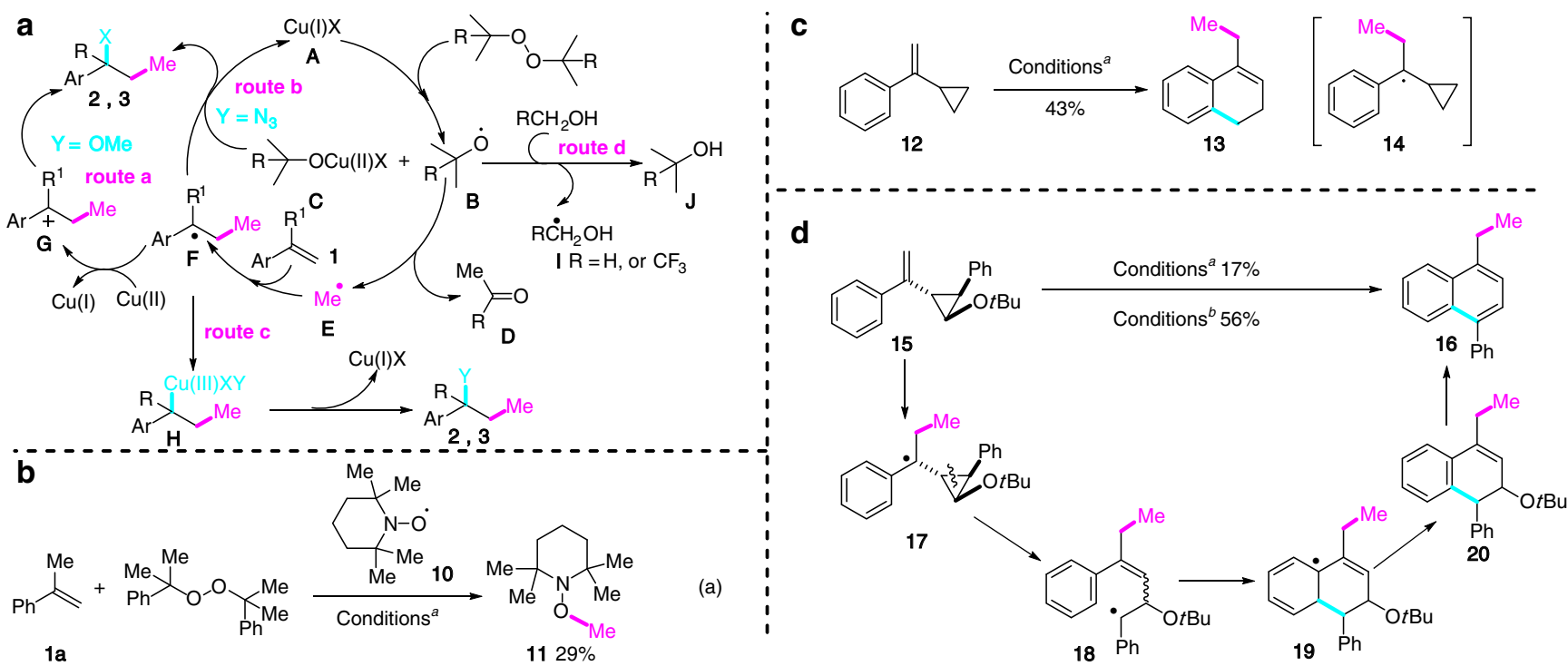

Fig. 5 Mechanistic proposal and control experiments. a Possible reaction pathways. b Radical trapping experiment. c Radical clock experiment d Super sensitive radical probe experiment. Conditions $a$ : $\mathbf{1 a}(0.2 \mathrm{mmol}), \mathrm{Cu}\left(\mathrm{BF}_{4}\right)_{2} \cdot 6 \mathrm{H}_{2} \mathrm{O}\left(0.2\right.$ equiv), $\mathbf{L 1}\left(0.3\right.$ equiv), DCP (4.0 equiv), $\mathrm{Na}_{2} \mathrm{HPO} \mathrm{H}_{4}(0.2$ equiv), $\mathrm{MeOH}(2.0 \mathrm{~mL}, c 0.1 \mathrm{M}), 120^{\circ} \mathrm{C}, 4 \mathrm{~h}$; Conditions b: $1 \mathbf{a}(0.2 \mathrm{mmol}), \mathrm{DTBP}(0.8 \mathrm{mmol}), \mathrm{LiN}_{3}(0.5 \mathrm{mmol}), \mathrm{CuSO}_{4}(0.002 \mathrm{mmol}, 0.1 \mathrm{equiv}), \mathbf{L 2}(0.06$ $\mathrm{mmol}), \mathrm{tBuOH}(2.0 \mathrm{~mL}, \mathrm{c} 0.1 \mathrm{M}), 120^{\circ} \mathrm{C}$

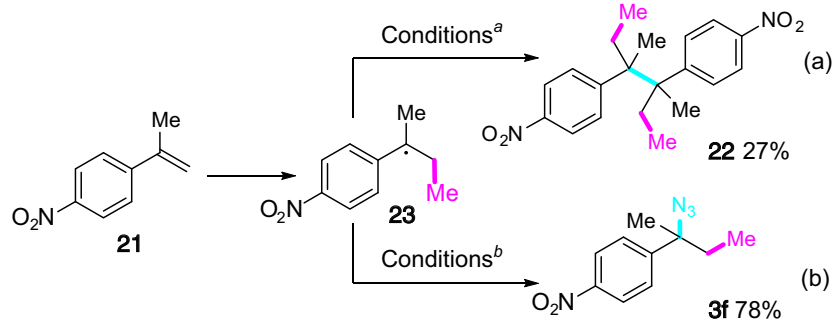

Fig. 6 Mechanistic divergence between methoxy methylation and azido methylation. a: $21(0.2 \mathrm{mmol}), \mathrm{Cu}\left(\mathrm{BF}_{4}\right)_{2} \cdot 6 \mathrm{H}_{2} \mathrm{O}(0.2$ equiv), $\mathbf{L 1}(0.3$ equiv), $\mathrm{DCP}$ (4.0 equiv), $\mathrm{Na}_{2} \mathrm{HPO}_{4}$ (0.2 equiv), $\mathrm{MeOH}(2.0 \mathrm{~mL}, \mathrm{c} 0.1 \mathrm{M}), 120^{\circ} \mathrm{C}$, 4 h; b: $21(0.2 \mathrm{mmol}), \mathrm{DTBP}(0.8 \mathrm{mmol}), \mathrm{LiN}_{3}(0.5 \mathrm{mmol}), \mathrm{CuSO}_{4}(0.002$ mmol, 0.1 equiv), $\mathbf{L 2}(0.06 \mathrm{mmol}), \mathrm{tBuOH}(2.0 \mathrm{~mL}, \mathrm{c} 0.1 \mathrm{M}), 120^{\circ} \mathrm{C}$

catalyzed) would, therefore, have a longer half-life than that generated under methoxy methylation conditions $[\mathrm{Cu}$ $\left(\mathrm{BF}_{4}\right)_{2} \cdot 6 \mathrm{H}_{2} \mathrm{O}$-catalyzed], hence the clean formation of product 16. This led us to hypothesize that the $\mathrm{C}-\mathrm{O}$ bond formation in the present alkoxy methylation went through cationic intermediate (route a, Fig. 5a), whereas the $\mathrm{C}-\mathrm{N}$ bond formation in the azido methylation proceeded via the $\mathrm{Cu}$-mediated azide transfer process (route b or c, Fig. 5a).

In accordance with the aforementioned reaction manifolds, 1,2-methoxy methylation of 1-methyl-1-(4-nitrophenyl)ethylene (21) under standard conditions afforded a significant amount of dimer 22 and only a trace amount of the desired methoxy methylation product (Fig. 6a). The presence of the strong electron-withdrawing nitro group on the phenyl ring might significantly reduce the rate of the oxidation of benzyl radical 23 to carbenium, blocking therefore the methoxylation process. It underwent instead the dimerization to afford 22. On the other hand, treatment of $\mathbf{2 1}$ under standard azido methylation conditions afforded the three-component adduct $3 \mathrm{f}$ in $78 \%$ yield together with a small amount of dimer 22 (Fig. 6b). The result supported the notion that oxidation of radical to cation is not involved in the azidation step and the azido group was transferred directly to the radical $\mathbf{2 3}$ via presumably a $\mathrm{Cu}$-mediated redox transfer process. The azide transfer reaction was apparently faster than the dimerization process under our optimized azido methylation conditions. It is also worth noting that dimer was rarely observed under the optimized methoxy methylation of alkenes due presumably to the rapid oxidation of benzyl radical to benzyl cation (except for 21), while it was very often observed as a side product in the azido methylation process due to the relatively long-lived benzyl radical species. Finally, performing the azidomethylation of a-methylstyrene (1a) in $\mathrm{MeOH}$ and $t \mathrm{BuOH} / \mathrm{MeOH}(\mathrm{v} / \mathrm{v}=4: 1)$ under otherwise standard conditions afforded the desired product $\mathbf{3 a}$ in yields of 46 and $62 \%$, respectively. The potential competitive reaction leading to the 1,2methoxy methylated product $\mathbf{2 a}$ was not observed. This result reinforced the hypothesis that benzyl cation might not be involved in the azidomethylation of alkenes.

At the outset of this research, we were concerned about the hydrogen abstraction of $\mathrm{MeOH}$ by tert-alkoxy radical $\mathbf{B}$ to generate the hydroxymethyl radical I (route d, Fig. 5a). This process has indeed been exploited in the difunctionalization of activated alkenes ${ }^{69,70}$. Two pathways, namely, thermal decomposition and reduction by $\mathrm{Cu}(\mathrm{I})$ salt, may contribute to the generation of the radical $\mathbf{B}$ from the peroxide. The formal process generates two molecules of alkoxy radical $\mathbf{B}$, while the latter produces one molecule of $\mathbf{B}$ and one molecule of copper tertbutoxide $\mathbf{C}$. Therefore, it was difficult to quantify the ratio of $\beta$ scission of $\mathbf{B}$ (generating $\mathrm{Me} \bullet$ ) vs $\mathrm{H}$-abstraction of $\mathrm{MeOH}$ by $\mathbf{B}$ (leading to $\bullet \mathrm{CH}_{2} \mathrm{OH}$ ) based on the ratio of acetophenone (D) vs 2phenylpropan-2-ol (J). Nevertheless, the high $\mathbf{J} / \mathbf{D}$ ratio $(3 / 1)$ we obtained for the methylative methoxylation of $a$-methylstyrene (1a) indicated that route $\mathrm{d}$, a thermodynamically favorable process (BDE of $\mathrm{H}-\mathrm{CH}_{2} \mathrm{OH}: 96.06 \pm 0.15 \mathrm{kcal} / \mathrm{mol} ; t \mathrm{BuO}-\mathrm{H}: 106.3 \pm 0.7$ $\mathrm{kcal} / \mathrm{mol}$ ), was indeed occurring in parallel. However, the sogenerated hydroxymethyl radical I did not interfere with the methylation process probably due to the pronounced nucleophilic nature of this radical or its rapid oxidation to formaldehyde.

In summary, we reported the $\mathrm{Cu}$-catalyzed carboalkoxylation, carboazidation, carbocycloetherification, carbolactonization, and carbocycloamination of alkenes using dicumyl peroxide (DCP) or di-tert-butyl peroxide (DTBP) as methyl sources. A diverse set of 
styrene derivatives were converted to the methylated ethers, azides, tetrahydrofurans, tetrahydropyrans, $\gamma$-lactones, and pyrrolidines with concurrent generation of a quaternary carbon in good to excellent yields. The results of control experiments suggested that the 1,2-alkoxy methylation of alkenes went through a radicalcation crossover mechanism, whereas the azido methylation proceeded via a radical addition and $\mathrm{Cu}$-mediated redox azide transfer process. This mechanistic insight would serve as a guideline in our searching for new alkene difunctionalization protocols.

\section{Methods}

Three-component 1,2-alkoxy methylation of alkenes. A screw cap tube was charged with $\mathrm{Cu}\left(\mathrm{BF}_{4}\right)_{2} \cdot 6 \mathrm{H}_{2} \mathrm{O}$ (13.8 mg, $\left.0.0400 \mathrm{mmol}\right), 4,4$ '-dimethoxy-2,2'-bipyridine $\mathbf{L 1}(13.0 \mathrm{mg}, 0.0601 \mathrm{mmol}), \mathrm{Na}_{2} \mathrm{HPO}_{4}(5.7 \mathrm{mg}, 0.0402 \mathrm{mmol})$ and $\mathrm{R}^{3} \mathrm{OH}$ $(2.0 \mathrm{~mL})$. The mixture was stirred at room temperature for $30 \mathrm{~min}$, then substrate 1 $(0.2 \mathrm{mmol}, 1.0$ equiv) and DCP $(216.2 \mathrm{mg}, 0.800 \mathrm{mmol})$ or DTBP $(0.15 \mathrm{~mL}, 4.0$ equiv) were added to the above mixture. After being stirred for $4 \mathrm{~h}$ at $120^{\circ} \mathrm{C}$ under $\mathrm{N}_{2}$ atmosphere, the reaction mixture was quenched with water and the aqueous phase was extracted with EtOAc. The organic extracts were washed with brine, dried over $\mathrm{Na}_{2} \mathrm{SO}_{4}$. The solvent was removed under reduced pressure. The residue was purified by flash chromatography to give 2 .

\section{Three-component 1,2-azido methylation of alkenes. A screw cap tube was} charged with $\mathrm{CuSO}_{4}(0.32 \mathrm{mg}, 0.002 \mathrm{mmol}, 0.01$ equiv), 1,10-phenanthroline $\mathbf{L} 2$ $(1.08 \mathrm{mg}, 0.003 \mathrm{mmol}, 0.03$ equiv) and $t \mathrm{BuOH}(2.0 \mathrm{~mL})$. The mixture was stirred at $40^{\circ} \mathrm{C}$ for $30 \mathrm{~min}$, then cooled to room temperature. Substrate $1(0.2 \mathrm{mmol}, 1.0$ equiv), $\operatorname{LiN}_{3}(20 \% \mathrm{w} / \mathrm{w}, 0.12 \mathrm{~mL}, 2.5$ equiv) and DTBP $(0.15 \mathrm{~mL}, 4.0$ equiv) were added to the above mixture, and the reaction mixture was stirred at $120^{\circ} \mathrm{C}$ for $8 \mathrm{~h}$ under $\mathrm{N}_{2}$ atmosphere. The reaction was quenched with water and the aqueous phase was extracted with EtOAc. The organic extracts were washed with brine, dried over $\mathrm{Na}_{2} \mathrm{SO}_{4}$. The solvent was removed under reduced pressure. The residue was purified by flash chromatography to give 3 .

Methylative cycloetherification. A screw cap tube was charged with $\mathrm{Cu}(\mathrm{OTf})_{2}$ (14.5 mg, $0.04 \mathrm{mmol}, 0.2$ equiv), L1 ( $13.0 \mathrm{mg}, 0.06 \mathrm{mmol}, 0.03$ equiv) and $\mathrm{CF}_{3} \mathrm{CH}_{2} \mathrm{OH}(2.0 \mathrm{~mL})$. The mixture was stirred at room temperature for $30 \mathrm{~min}$. Substrate 4 ( $0.2 \mathrm{mmol}, 1.0$ equiv), $\mathrm{Na}_{3} \mathrm{PO}_{4}(6.5 \mathrm{mg}, 0.04 \mathrm{mmol}, 0.2$ equiv) and DTBP $(0.15 \mathrm{~mL}, 4.0$ equiv) were added to the above mixture, and the reaction mixture was stirred at $120^{\circ} \mathrm{C}$ for $6 \mathrm{~h}$ under $\mathrm{N}_{2}$ atmosphere. The reaction was quenched with water, and the aqueous phase was extracted with EtOAc. The organic extracts were washed with brine, dried over $\mathrm{Na}_{2} \mathrm{SO}_{4}$. The solvent was removed under reduced pressure. The residue was purified by flash chromatography to give $\mathbf{5}$.

Methylative lactonization. A screw cap tube was charged with $\mathrm{CuSO}_{4}(6.4 \mathrm{mg}$, $0.04 \mathrm{mmol}, 0.2$ equiv), 1,10-phenanthroline $\mathbf{L} 2$ ( $10.8 \mathrm{mg}, 0.06 \mathrm{mmol}, 0.03$ equiv) and $\mathrm{CF}_{3} \mathrm{CH}_{2} \mathrm{OH}(2.0 \mathrm{~mL})$. The mixture was stirred at room temperature for 30 min. Substrate 6 ( $0.2 \mathrm{mmol}, 1.0$ equiv), $\mathrm{Na}_{3} \mathrm{PO}_{4}(9.8 \mathrm{mg}, 0.06 \mathrm{mmol}, 0.3$ equiv) and DTBP $(0.15 \mathrm{~mL}, 4.0$ equiv) were added to the above mixture, and the reaction mixture was stirred at $120^{\circ} \mathrm{C}$ for $6 \mathrm{~h}$ under $\mathrm{N}_{2}$ atmosphere. The reaction was quenched with water and extracted with EtOAc. The organic extracts were washed with brine, dried over $\mathrm{Na}_{2} \mathrm{SO}_{4}$. The solvent was removed under reduced pressure. The residue was purified by flash chromatography to give 7 .

Methylative cycloamination. A screw cap tube was charged with $\mathrm{Cu}(\mathrm{OAc})_{2}$ (7.3 mg, $0.04 \mathrm{mmol}, 0.2$ equiv), 1,10-phenanthroline $\mathbf{L} 2(10.8 \mathrm{mg}, 0.06 \mathrm{mmol}, 0.03$ equiv), and $t \mathrm{BuOH}(2.0 \mathrm{~mL})$. The mixture was stirred at room temperature for $30 \mathrm{~min}$. Substrate $8\left(0.2 \mathrm{mmol}, 1.0\right.$ equiv), $\mathrm{Na}_{3} \mathrm{PO}_{4}(6.5 \mathrm{mg}, 0.04 \mathrm{mmol}, 0.2$ equiv) and DTBP $(0.15 \mathrm{~mL}, 4.0$ equiv) were added to the above mixture, and the reaction mixture was stirred at $120^{\circ} \mathrm{C}$ for $3 \mathrm{~h}$ under $\mathrm{N}_{2}$ atmosphere. The reaction was quenched with water and the mixture was extracted with EtOAc. The organic extracts were washed with brine, dried over $\mathrm{Na}_{2} \mathrm{SO}_{4}$. The solvent was removed under reduced pressure. The residue was purified by flash chromatography to give 9

\section{Data availability}

The authors declare that the data supporting the findings of this study are available within the paper and Supplementary Information, as well as from the authors upon request.

Received: 13 June 2018 Accepted: 21 August 2018

Published online: 13 September 2018

\section{References}

1. Schönherr, H. \& Cernak, T. Profound methyl effects in drug discovery and a call for new C-H methylation reactions. Angew. Chem., Int. Ed. 52, 12256-12267 (2013).

2. Yan, G., Borah, A. J., Wang, L. \& Yang, M. Recent advances in transition metal-catalyzed methylation reactions. Adv. Synth. Catal. 357, 1333-1350 (2015).

3. Hu, L., Liu, Y. A. \& Liao, X. Recent progress in methylation of (hetero)arenes by cross-coupling or C-H activation. Synlett 29, 375-382 (2018).

4. Studer, A. A. "Renaissance" in radical trifluoromethylation. Angew. Chem., Int. Ed. 51, 8950-8958 (2012)

5. Merino, E. \& Nevado, C. Addition of $\mathrm{CF}_{3}$ across unsaturated moieties: a powerful functionalization tool. Chem. Soc. Rev. 43, 6598-6608 (2014)

6. McGrath, N. A., Brichacek, M. \& Njardarson, J. T. A graphical journey of innovative organic architectures that have improved our lives. J. Chem. Educ. 87, 1348-1349 (2010)

7. Charpentier, J., Früh, N. \& Togni, A. Electrophilic trifluoromethylation by use of hypervalent iodine reagents. Chem. Rev. 115, 650-682 (2015).

8. Mukaiyama, T., et al. Oxidation-reduction hydration of olefins with molecular oxygen and 2-propanol catalyzed by bis(acetylacetonato)cobalt(II). Chem. Lett. 18, 449-452 (1989).

9. Waser, J., Gaspar, B., Nambu, H. \& Carreira, E. M. Hydrazines and azides via the metal-catalyzed hydrohydrazination and hydroazidation of olefins. J. Am. Chem. Soc. 128, 11693-11712 (2006).

10. Barker, T. J. \& Boger, D. L. Fe(III)/ $/ \mathrm{NaBH}_{4}$-mediated free radical hydrofluorination of unactivated alkenes. J. Am. Chem. Soc. 134, 13588-13591 (2012).

11. Shigehisa, H., et al. Catalytic synthesis of saturated oxygen heterocycles by hydrofunctionalization of unactivated olefins: unprotected and protected strategies. J. Am. Chem. Soc. 138, 10597-10604 (2016).

12. Girijavallabhan, V., Alvarez, C. \& Njoroge, F. G. Regioselective cobaltcatalyzed addition of sulfides to unactivated alkenes. J. Org. Chem. 76, 6442-6446 (2011)

13. Green, S. A., Matos, J. L. M., Yagi, A. \& Shenvi, R. A. Branch-selective hydroarylation: iodoarene-olefin cross-coupling. J. Am. Chem. Soc. 138 , 12779-12782 (2016)

14. King, S. M., Ma, X. \& Herzon, S. B. A method for the selective hydrogenation of alkenyl halides to alkyl halides. J. Am. Chem. Soc. 136, 6884-6887 (2014).

15. Dao, H. T., Li, C., Michaudel, Q., Maxwell, B. D. \& Baran, P. S. Hydromethylation of unactivated olefins. J. Am. Chem. Soc. 137, 8046-8049 (2015).

16. Crossley, S. W. M., Obradors, C., Martinez, R. M. \& Shenvi, R. A. Mn-, Feand Co-catalyzed radical hydrofunctionalizations of olefins. Chem. Rev. 116, 8912-9000 (2016)

17. Maimone, T. J., Shi, J., Ashida, S. \& Baran, P. S. Total synthesis of vinigrol. J. Am. Chem. Soc. 131, 17066-17067 (2009).

18. Poulin, J., Grisé-Bard, C. M. \& Barriault, L. A formal synthesis of vinigrol. Angew. Chem., Int. Ed. 51, 2111-2114 (2012).

19. Gray, P. \& Williams, A. The thermochemistry and reactivity of alkoxyl radicals. Chem. Rev. 59, 239-328 (1959).

20. Maeda, M., Nushi, K. \& Kawazoe, Y. Studies on chemical alterations of nucleic acids and their components-VII: C-alkylation of purine bases through free radical process catalyzed by ferrous ion. Tetrahedron 30, 2677-2682 (1974).

21. Zady, M. F. \& Wong, J. L. Kinetics and mechanism of carbon-8 methylation of purine bases and nucleosides by methyl radical. J. Am. Chem. Soc. 99, 5096-5101 (1977)

22. Minisci, F., Vismara, E. \& Fontana, F. Recent developments of free-radical substitutions of heteroaromatic bases. Heterocycles 28, 489-519 (1989).

23. Zhang, Y., Feng, J. \& Li, C.-J. Palladium-catalyzed methylation of aryl C-H bond by using peroxides. J. Am. Chem. Soc. 130, 2900-2901 (2008).

24. Kubo, T. \& Chatani, N. Dicumyl peroxide as a methylating reagent in the $\mathrm{Ni}$ catalyzed methylation of ortho $\mathrm{C}-\mathrm{H}$ bonds in aromatic amides. Org. Lett. 18, 1698-1701 (2016)

25. Zhang, P.-Z., et al. Metal-free radical C-H methylation of pyrimidinones and pyridinones with dicumyl peroxide. Green. Chem. 19, 919-923 (2017).

26. $\mathrm{Li}, \mathrm{Q}$., et al. Cobalt-catalyzed $\mathrm{C}\left(\mathrm{sp}^{2}\right)-\mathrm{H}$ methylation by using Dicumyl peroxide as both the methylating reagent and hydrogen acceptor. Chem. Eur. J. 22, 12286-12289 (2016).

27. Xia, Q., Liu, X., Zhang, Y., Chen, C. \& Chen, W. Copper-catalyzed Nmethylation of amides and O-methylation of carboxylic acids by using peroxides as the methylating reagents. Org. Lett. 15, 3326-3329 (2013).

28. Zhu, Y., et al. Copper-catalyzed methyl esterification reactions via $\mathrm{C}-\mathrm{C}$ bond cleavage. J. Org. Chem. 78, 9898-9905 (2013).

29. Teng, F., Cheng, J. \& Yu, J.-T. Copper-catalyzed N-methylation/ethylation of sulfoximines. Org. Biomol. Chem. 13, 9934-9937 (2015)

30. Bao, Y., et al. Copper-catalyzed radical methylation/C-H amination/oxidation cascade for the synthesis of quinazolinones. J. Org. Chem. 80, 4736-4742 (2015). 
31. Xu, Z., Yan, C. \& Liu, Z.-Q. A free-radical cascade methylation/cyclization of $\mathrm{N}$-arylacrylamides and isocyanides with dicumyl peroxide. Org. Lett. 16, 5670-5673 (2014).

32. Dai, Q., et al. Di-tert butyl peroxide-promoted sequential methylation and intramolecular aromatization of isonitriles. Adv. Synth. Catal. 356, 3341-3346 (2014).

33. Xu, Z., Hang, Z. \& Liu, Z.-Q. Free-radical triggered ordered domino reaction: an approach to $\mathrm{C}-\mathrm{C}$ bond formation via selective functionalization of $\alpha$ hydroxyl- $\left(\mathrm{sp}^{3}\right) \mathrm{C}-\mathrm{H}$ in fluorinated alcohols. Org. Lett. 18, 4470-4473 (2016).

34. Zhang, X., et al. Selective oxidative coupling reaction of isocyanides using peroxide as switchable alkylating and alkoxylating reagent. Adv. Synth. Catal. 360, 272-277 (2018).

35. Fan, J.-H., et al. Iron-catalyzed oxidative arylmethylation of activated alkenes using a peroxide as the methyl source. Synlett 25, 657-660 (2014).

36. Dai, Q., et al. The carbomethylation of arylacrylamides leading to 3-ethyl-3substituted indolin-2-one by cascade radical addition/cyclization. Chem. Commun. 50, 3865-3867 (2014).

37. Tan, F.-L., Song, R.-J., Hu, M. \& Li, J.-H. Metal-free oxidative 1, 2 arylmethylation cascades of $\mathrm{N}$-(arylsulfonyl)acrylamides using peroxides as the methyl resource. Org. Lett. 18, 3198-3201 (2016).

38. Tan, F.-L., Hu, M., Song, R.-J. \& Li, J.-H. Metal-free annulation cascades of 1,7-enynes using di-tert-butyl peroxide as the methyl source towards the synthesis of polyheterocyclic scaffolds. Adv. Synth. Catal. 359, 3602-3610 (2017).

39. Dai, Q., Jiang, Y., Yu, J.-T. \& Cheng, J. Peroxide: A novel methylating reagent. Synthesis 48, 329-339 (2016).

40. Herk, L., Stefani, A. \& Szwarc, M. Methyl affinities of some compounds related to acrylates and acrylonitriles. reactivities of conjugated systems involving atoms other than carbon. J. Am. Chem. Soc. 83, 3008-3011 (1961).

41. Minisci, F., Mondelli, R., Gardini, G. P. \& Porta, O. Nucleophilic character of alkyl radicals-VII: substituent effects on the homolytic alkylation of protonated heteroaromatic bases with methyl, primary, secondary and tertiary alkyl radicals. Tetrahedron 28, 2403-2413 (1972).

42. Zytowski, T. \& Fischer, H. Absolute rate constants for the addition of methyl radicals to alkenes in solution: new evidence for polar interactions. J. Am. Chem. Soc. 118, 437-439 (1996).

43. Zhu, N., Zhao, J. \& Bao, H. Iron catalyzed methylation and ethylation of vinyl arenes. Chem. Sci. 8, 2081-2085 (2017).

44. Wang, Y., et al. Alkene oxyalkylation enabled by merging rhenium catalysis with hypervalent iodine(III) reagents via decarboxylation. J. Am. Chem. Soc 135, 18048-18051 (2013).

45. Tlahuext-Aca, A., Garza-Sanchez, R. A. \& Glorius, F. Multicomponent oxyalkylation of styrenes enabled by hydrogen-bond-assisted photoinduced electron transfer. Angew. Chem., Int. Ed. 56, 3708-3711 (2017).

46. Jian, W., Ge, L., Jiao, Y., Qian, B. \& Bao, H. Iron-catalyzed decarboxylative alkyl etherification of vinylarenes with aliphatic acids as the alkyl source. Angew. Chem., Int. Ed. 56, 3650-3654 (2017).

47. Li, Y., et al. Copper-catalyzed regioselective 1,2-alkylesterification of dienes to allylic esters. Org. Lett. 18, 392-395 (2016)

48. Wu, K., Liang, Y. \& Jiao, N. Azidation in the difunctionalization of olefins. Molecules 21, 352 (2016).

49. Renaud, P., Ollivier, C. \& Panchaud, P. Radical carboazidation of alkenes: an efficient tool for the preparation of pyrrolidinone derivatives. Angew. Chem., Int. Ed. 41, 3460-3462 (2002).

50. Weidner, K., Giroult, A., Panchaud, P. \& Renaud, P. Efficient carboazidation of alkenes using a radical desulfonylative azide transfer process. J. Am. Chem. Soc. 132, 17511-17515 (2010).

51. Bunescu, A., Ha, T. M., Wang, Q. \& Zhu, J. Copper-catalyzed threecomponent carboazidation of alkenes with acetonitrile and sodium azide. Angew. Chem., Int. Ed. 56, 10555-10558 (2017).

52. Qian, B., Chen, S., Wang, T., Zhang, X. \& Bao, H. Iron-catalyzed carboamination of olefins: synthesis of amines and disubstituted $\beta$-amino acids. J. Am. Chem. Soc. 139, 13076-13082 (2017).

53. Liu, Y.-Y., Yang, X.-H., Song, R.-J., Luo, S. \& Li, J.-H. Oxidative 1,2carboamination of alkenes with alkyl nitriles and amines toward $\gamma$-amino alkyl nitriles. Nat. Commun. 8, 14720-14725 (2017).

54. Wolfe, J. P. Palladium-catalyzed carboetherification and carboamination reactions of $\gamma$-hydroxy- and $\gamma$-aminoalkenes for the synthesis of tetrahydrofurans and pyrrolidines. Eur. J. Org. Chem. 571-582 (2007).

55. Chemler, S. R. \& Fuller, P. H. Heterocycle synthesis by copper facilitated addition of heteroatoms to alkenes, alkynes and arenes. Chem. Soc. Rev. 36, 1153-1160 (2007).

56. Ha, T. M., Wang, Q. \& Zhu, J. Copper-catalysed cyanoalkylative cycloetherification of alkenes to 1,3-dihydroisobenzofurans: development and application to the synthesis of citalopram. Chem. Commun. 52, 11100-11103 (2016).

57. Connolly, J. D. \& Hill, R. A. Dictionary of terpenoids. Vol. 1, 476-545 (Chapman and Hall, London, 1991).
58. Collins, I. Saturated and unsaturated lactones. J. Chem. Soc., Perkin Trans. 1, 1377-1395 (1999).

59. Corey, E. J. \& Kang, M.-C. A new and general synthesis of polycyclic $\gamma$ lactones by double annulation. J. Am. Chem. Soc. 106, 5384-5385 (1984).

60. Huang, L., Jiang, H., Qi, C. \& Liu, X. Copper-catalyzed intermolecular oxidative [3+2] cycloaddition between alkenes and anhydrides: a new synthetic approach to $\gamma$-lactones. J. Am. Chem. Soc. 132, 17652-17654 (2010).

61. Wei, X.-J., et al. A novel intermolecular synthesis of $\gamma$-lactones via visible-light photoredox catalysis. Org. Lett. 15, 6054-6057 (2013).

62. Ha, T. M., Chatalova-Sazepin, C., Wang, Q. \& Zhu, J. Copper-catalyzed formal $[2+2+1]$ heteroannulation of alkenes, alkylnitriles, and water: method development and application to a total synthesis of $( \pm)$-Sacidumlignan D. Angew. Chem., Int. Ed. 55, 9249-9252 (2016).

63. Sha, W., Ni, S., Han, J. \& Pan, Y. Access to alkyl-substituted lactone via photoredox-catalyzed alkylation/lactonization of unsaturated carboxylic acids. Org. Lett. 19, 5900-5903 (2017).

64. Zhu, R. \& Buchwald, S. L. Versatile enantioselective synthesis of functionalized lactones via copper-catalyzed radical oxyfunctionalization of alkenes. J. Am. Chem. Soc. 137, 8069-8077 (2015).

65. Egami, H., Kawamura, S., Miyazaki, A. \& Sodeoka, M. Trifluoromethylation reactions for the synthesis of $\beta$-trifluoromethylamines. Angew. Chem., Int. Ed. 52, 7841-7844 (2013).

66. Lin, J.-S., et al. A dual-catalytic strategy to direct asymmetric radical aminotrifluoromethylation of alkenes. J. Am. Chem. Soc. 138, 9357-9360 (2016).

67. Newcomb, M. \& Chestney, D. L. A hypersensitive mechanistic probe for distinguishing between radical and carbocation intermediates. J. Am. Chem. Soc. 116, 9753-9754 (1994).

68. Um, C. \& Chemler, S. R. Synthesis of 2-aryl- and 2-vinylpyrrolidines via copper-catalyzed coupling of styrenes and dienes with potassium $\beta$ aminoethyl trifluoroborates. Org. Lett. 18, 2515-2518 (2016).

69. Meng, Y., Guo, L.-N., Wang, H. \& Duan, X.-H. Metal-free oxidative hydroxyalkylarylation of activated alkenes by direct $\mathrm{sp}^{3} \mathrm{C}-\mathrm{H}$ functionalization of alcohols. Chem. Commun. 49, 7540-7542 (2013).

70. Cheng, J.-K. \& Loh, T.-P. Copper- and cobalt-catalyzed direct coupling of $\mathrm{sp}^{3}$ a-carbon of alcohols with alkenes and hydroperoxides. J. Am. Chem. Soc. 137 42-45 (2015).

\section{Acknowledgements}

We thank EPFL (Switzerland), the Swiss National Science Foundation (SNSF 20020_155973; SNSF 20021_178846) and the Swiss National Centers of Competence in Research (NCCR- Chemical Biology) for financial support.

\section{Author contributions}

X.B., T.Y., T.M.H., Q.W., and J.Z. conceived and designed the experiments. X.B., T.Y., and T.M.H. carried out the experiments. X.B., T.Y., T.M.H., Q.W., and J.Z. interpreted the results and X.B., Q.W., and J.Z. co-wrote the manuscript.

\section{Additional information}

Supplementary Information accompanies this paper at https://doi.org/10.1038/s41467018-06246-6.

\section{Competing interests: The authors declare no competing interests.}

Reprints and permission information is available online at http://npg.nature.com/ reprintsandpermissions/

Publisher's note: Springer Nature remains neutral with regard to jurisdictional claims in published maps and institutional affiliations.

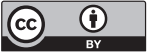

Open Access This article is licensed under a Creative Commons Attribution 4.0 International License, which permits use, sharing, adaptation, distribution and reproduction in any medium or format, as long as you give appropriate credit to the original author(s) and the source, provide a link to the Creative Commons license, and indicate if changes were made. The images or other third party material in this article are included in the article's Creative Commons license, unless indicated otherwise in a credit line to the material. If material is not included in the article's Creative Commons license and your intended use is not permitted by statutory regulation or exceeds the permitted use, you will need to obtain permission directly from the copyright holder. To view a copy of this license, visit http://creativecommons.org/ licenses/by/4.0/.

(C) The Author(s) 2018 